\title{
Defer surgery in operable breast cancer: how long is too long?
}

\author{
Sacha Roberts ${ }^{1} \cdot$ Aram Rojas $^{1} \cdot$ Giulia DiRaimo $^{1} \cdot$ Melanie Orlando $^{1} \cdot$ Mahir Gachabayov ${ }^{1} \cdot$ Maria Castaldi $^{1} \mathbb{1}$
}

Received: 2 February 2021 / Accepted: 28 September 2021 / Published online: 18 October 2021

(c) The Author(s), under exclusive licence to The Japanese Breast Cancer Society 2021

\begin{abstract}
Purpose The aim of this meta-analysis was to evaluate outcomes of surgery compared to primary endocrine therapy (PET) in patients with non-advanced, operable invasive breast cancer, and to determine if PET as initial therapy may safely postpone surgery.

Methods The MEDLINE, EMBASE, PubMed, and Cochrane Library were searched from database inception to July 2020 to identify eligible studies. Inclusion criteria were experimental or observational studies with at least one arm treated with PET and a second arm treated with surgery with or without PET. Local recurrence or progression of disease was defined as either failure of non-operative management (tumor failing to decrease in size and/or continuous local or distant tumor growth) or relapse of breast tumor after tumor downsizing following PET. Effect estimates were expressed in hazard ratio and $95 \%$ confidence intervals (HR (95\% CI)).

Results The analysis included six studies with 1499 unique patients. The median time to local progression of disease was 2.3 years. Patients treated with PET alone without surgery had a higher risk of local recurrence and or progression [HR (95\% CI): $\left.1.76(1.33,2.31) ; I^{2}=84 \% ; p<0.001\right]$. Patients treated with PET had more favorable outcomes in terms of overall survival [HR (95\% CI): $\left.1.24(1.06,1.46) ; I^{2}=70 \% ; p=0.008\right]$ and less favorable outcomes in breast cancer-specific survival [HR (95\% CI): $\left.1.13(0.98,1.31) ; I^{2}=41 \% ; p=0.10\right]$. The risk of publication bias was assessed to be high in reporting local recurrence rates and low in reporting distant recurrence rates.
\end{abstract}

Conclusion PET alone is inferior to surgery in the treatment of operable invasive breast cancer.

However, it may be acceptable to postpone curative breast cancer surgery without risk of progression for 1.1 years or longer.

Keywords Breast cancer $\cdot$ Surgery $\cdot$ Endocrine therapy $\cdot$ Tamoxifen $\cdot$ COVID-19

\section{Introduction}

The outbreak of severe acute respiratory syndrome coronavirus 2 (SARS-CoV-2) associated disease (COVID-19) has majorly impacted the distribution of healthcare resources around the world [1]. This has significantly altered how patients are screened and treated for recently diagnosed breast cancer. On March 26, 2020, the American Society of Breast Surgeons filed a joint statement with the American College of Radiology stating that all breast screening exams, including mammography, ultrasound, and MRI, were to be temporarily suspended until the COVID-19 pandemic

Maria Castaldi

maria.castaldi@wmchealth.org

1 Department of Surgery, Breast Surgery, Westchester Medical Center, New York Medical College School of Medicine, 100 Woods Rd, Valhalla, NY 10595, USA is better controlled [2]. Similarly, patients currently undergoing treatment for diagnosed breast cancer (BC) are also experiencing disrupted medical care [3]. In a survey that was completed by 377 breast care providers from large institutions and university affiliated hospitals in 41 different countries, 34\% reported a reduction in their overall workload by $\geq 50 \%$, and $13 \%$ indicated that breast care was relocated to reduce hospital visits [4].

The standard of care for patients diagnosed with localized breast cancer consists of a combination of surgery, radiation therapy, and systemic therapy [5]. However, various groups, including the National Comprehensive Cancer Network, recently published guidelines that support adjusted or delayed treatment plans for patients diagnosed with breast cancer during these unprecedented times $[3,6,7]$. One recommendation is the use of primary endocrine therapy (PET) as first line treatment preoperatively rather than definitive breast surgery. PET may be an attractive option for 
luminal-like tumors as it could minimize hospital admissions and delay elective surgeries [7]. Therefore, it is not surprising that in the aforementioned survey, $68 \%$ of responders considered initial endocrine treatment in patients diagnosed with hormone receptor-positive breast cancer with the intent to postpone surgery [4].

Approximately $75 \%$ of breast cancers are hormone receptor (HR)-positive, indicating estrogen receptor (ER) and progesterone receptor (PR) tumor expression [8]. Tamoxifen, fulvestrant, and aromatase inhibitors are the most common endocrine therapies used to treat breast cancer in both the neoadjuvant and adjuvant settings [9]. Though the gold standard of care for initial treatment of localized, early-stage breast cancer is surgery, there are various situations, in addition to suspension of elective and non-emergent surgery, for which PET may be the preferred first course of treatment. PET is often the preferred treatment for early-operable breast cancer if patients are elderly and unfit for surgery [10]. PET is also used as initial course of treatment to downstage primary breast tumor burden to aid in future resection [11].

Over the past few decades, the increasing use of PET as a preoperative, initial treatment for breast cancer instead of surgery has generated various studies comparing the longterm outcomes of patients who undergo solely endocrine therapy versus surgery. In 2010, a Cochrane review summarized the findings of seven studies on this topic, and they concluded that primary endocrine therapy is inferior to surgery with endocrine therapy for the local control of breast cancer in ER-unselected, medically fit older women [12]. However, since publication, various other groups have come forward with additional data, with some claiming that patients with ER-rich tumors do equally well on PET as compared to surgery [13]. The aim of this meta-analysis was to amalgamate all studies that have assessed the outcomes of PET versus surgery for patients diagnosed with early breast cancer to provide comprehensive evidence on the benefits or risks of PET in place of surgery. In turn, this study would delineate the possible long-term implications of treating early-operable breast cancer patients with solely PET when surgery is prohibited and reserved for only emergent procedures. Further, insight may be given on long-term delay or omission of surgery for local treatment of otherwise operable breast cancer.

\section{Materials and methods}

\section{Study design, search strategy, and research question}

This systematic review was performed according to the Cochrane Handbook for Systematic Reviews of Interventions [14]. In July 2020, a systematic search of studies in
PubMed, Ovid MEDLINE, and Embase was performed based on guidelines of the Preferred Reporting Items for Systematic Reviews and Meta-Analyses (PRISMA) [15] and Meta-analysis Of Observational Studies in Epidemiology (MOOSE) [16]. The protocol of this systematic review was developed a priori and published [17]. Following MeSH terms were used for the literature search: 'breast cancer', 'endocrine therapy', 'surgery' combined with the Boolean operator 'AND' and all synonyms combined with the Boolean operator ' $O R$. The research question was formulated within the PICOT(S) framework as follows:

(P) Population: Adults older than 18 years with breast cancer.

(I) Intervention: Primary endocrine therapy.

(C) Comparator: Surgery.

(O) Outcomes: local and/or distant recurrence (progression), overall and cancer-specific survival, all-cause and cancer-specific mortality.

(T) Timing: Long-term.

(S) Setting: In- and outpatient.

\section{Eligibility criteria, endpoints, and definitions}

Inclusion criteria are any experimental or observational design study comparatively evaluating long-term outcomes of PET and surgery for breast cancer. Studies comparing one of the interventions of interest to a non-relevant intervention, descriptive studies, and summary design studies were excluded. The primary endpoint of this review was local and distant cancer recurrence or progression of disease, local or distant. Secondary endpoints included overall and cancer-specific survival as well as all-cause and cancer-specific mortality. Local recurrence or progression of disease was defined as either failure of non-operative management whereby the tumor does not decrease in size, has continuous local or distant tumor growth, or recurs in the breast after tumor downsizing or disappearance of tumor following PET. In other words, local recurrence and progression were defined as any situation when either the primary breast cancer did not respond to the treatment, i.e., size did not change or increased, or regrowth of tumor after a period of time that it had disappeared. Progression of disease was also defined as occurrence of disease in axillary lymph nodes or distant organs when uninvolved on initiation of PET, regardless of the status of response of the primary breast cancer to the treatment.

\section{Study selection and data extraction}

After removing the duplicates, screening of all titles, abstracts, and full-text articles of potentially eligible studies was performed by two reviewers (SR and AR) working independently and in duplicate. Any disagreements at full-text 
screening were resolved by consensus. Data extraction of each eligible study was also performed independently and in duplicate by the same two reviewers. Following variables were extracted and inserted in predefined Microsoft Excel tables: authors, year and journal of publication, study ID, study design, baseline characteristics, and oncological outcomes.

\section{Statistical analysis}

The risk of bias was assessed by reviewers working independently and in duplicate using the Cochrane assessment tool for RCTs. Disagreements were resolved by consensus. A meta-analysis of hazard ratios (HR) was performed in two stages. The log-rank Observed minus Expected events $(O-E)$ as well as the log-rank Variance $(V)$ were estimated for each included individual study using randomization ratio, numbers of randomized and analyzed patients, number of events, and follow-up details (employing direct or indirect methods). A fixed effect model of $\operatorname{Exp}[O-E) / \mathrm{Var}]$ method was utilized for the meta-analysis of hazard ratios. Effect estimates were expressed in HRs with corresponding 95\% confidence intervals (HR $(95 \% \mathrm{CI})$ ). Statistical heterogeneity was evaluated with the $\chi^{2}$ test, and inconsistency was estimated using the $\mathrm{I}^{2}$ statistic [18]. The risk of publication bias was evaluated through visual assessment of symmetry on the funnel plots of HR and standard error of logHR. Statistical analysis was conducted using Review Manager (RevMan; version 5.1 for Mac; Nordic Cochrane Centre, Cochrane Collaboration; Copenhagen, Denmark).

\section{Results}

A total of 12,708 potential studies were identified by the systematic search. Of these, 1,133 titles were selected for abstract screening. Of the 1133 screened abstracts, 39 fulltext manuscripts were assessed for eligibility. Ultimately, a total of six randomized controlled trials were selected, with 1499 unique patients. The PRISMA flow diagram detailing the study selection process is shown in Fig. 1. The findings of quality assessment are depicted in risk of bias summary and graph (Fig. 2). Overall bias risk was found to be low.

\section{Study characteristics}

Characteristics of the included studies were summarized in Table 1. The six selected studies [19-24] were published from 2000 to 2011. The sample sizes ranged from 75 to 474 and all consisted of women $\geq 70$ years old diagnosed with breast cancer. The selected studies compared surgery (typically mastectomy) \pm tamoxifen vs. PET (typically tamoxifen). Additional details on the selected studies are shown in Table 2.

\section{Local and distant recurrence (progression) rates}

Patients treated with PET had a higher risk of local recurrence [HR (95\% CI): $\left.1.76(1.33,2.31) ; I^{2}=84 \% ; p<0.001\right]$ yet a decreased risk of distant recurrence [HR $(95 \% \mathrm{CI}): 0.76$ $\left.(0.59,0.98), I^{2}=0 \% ; p=0.04\right]$ (Fig. 3). The way each study defined local and distant recurrence is outlined in Table 1. The median time to local recurrence was assessed for the PET arm of each study to elucidate how long it may be safe to treat patients with solely PET to postpone surgery. Five [20-24] of the selected studies plus one additional study [25] that was only included in the qualitative analysis reported on time to local disease progression. Time to local disease progression for patients treated with solely PET ranged from 1.1 [22] to 5.8 [25] years, with four studies reporting median time to local progression of 1.7 [21], 2.1 [20], 2.5 [24], and 3.3 [23] years from the initiation of endocrine therapy.

\section{Overall and cancer-specific survival rates}

Patients treated with PET had more favorable outcomes in terms of overall survival as compared to those treated with surgery \pm PET with considerable among-study statistical heterogeneity [HR (95\% CI): $1.24(1.06,1.46) ; I^{2}=70 \%$; $p=0.008]$. However, breast cancer-specific survival rates did not significantly differ between PET and surgery \pm PET with moderate heterogeneity [HR (95\% CI): $1.13(0.98,1.31)$; $\left.I^{2}=41 \% ; p=0.10\right]$ (Fig. 4).

\section{All-cause and cancer-specific mortality rates}

All-cause [HR (95\% CI): $1.09(0.97,1.24) ; I^{2}=76 \%$; $p=0.16]$ and cancer-specific mortality rates [HR (95\% CI): $\left.1.11(0.91,1.36) ; I^{2}=64 \% ; p=0.31\right]$ did not significantly differ between patients treated with PET and those treated with surgery \pm PET with substantial among-study statistical heterogeneity (Fig. 5).

\section{Subgroup meta-analysis}

A subgroup meta-analysis was performed after excluding studies, in which the comparator arm was surgery alone. The findings of local and distant recurrence rates were not significantly different in the subgroup meta-analysis (Supplements 1 and 2). Overall [HR (95\% CI): 1.17 (0.99, 1.38); $\left.I^{2}=58 \% ; p=0.07\right]$ and breast cancer-specific survival rates [HR (95\% CI): $\left.1.13(0.96,1.33) ; I^{2}=67 \% ; p=0.13\right] \mathrm{did}$ not significantly differ between the arms (Supplements 3 and 4). All-cause mortality rates favored surgery \pm PET [HR (95\% CI): $\left.1.21(1.05,1.40) ; I^{2}=0 \% ; p=0.01\right]$, whereas 


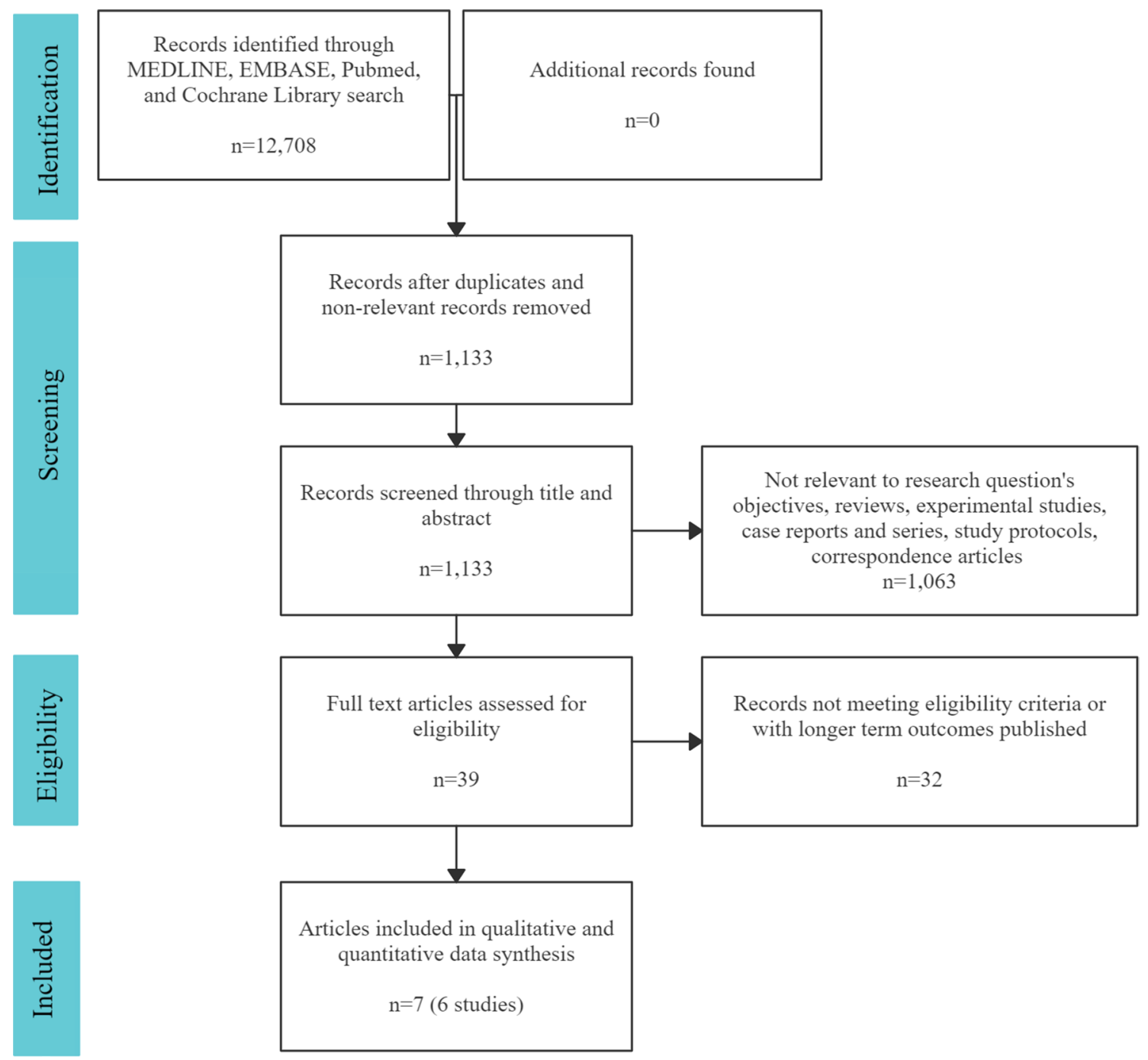

Fig. 1 PRISMA flow diagram

cancer-specific mortality rates [HR (95\% CI): 1.21 (0.96, $1.52) ; I^{2}=65 \% ; p=0.10$ ] did not significantly differ between the arms (Supplements 5 and 6).

\section{Publication bias}

The risk of publication bias was assessed to be high in reporting local recurrence rates and low in reporting distant recurrence rates (Fig. 6).

\section{Discussion}

Cancer care was severely impacted by the COVID-19 pandemic. Significant reductions in clinical activity delayed cancer operations to preserve resources and protect patients and staff. The normal operating cadre is a mix of emergent, urgent and elective cases. In phase 1 of the pandemic, elective cases were removed, most semi-urgent cases were postponed, and in pandemic hot spots, urgent cases were also delayed [26]. This ultimately led to an enormous backlog of patients at the end of the surge that required operations.

In the United States, 1.8 million patients are diagnosed with cancer each year [27]. Therefore, during 3-month pandemic window, this equates to 150,000 new cancer cases per month. Acute disruption in the ability to deliver care for approximately 3 months during the height of the pandemic affected nearly 0.5 million patients diagnosed with cancer during the peak phase of SARS-CoV-2 virus outbreak. Of those $1.8 \mathrm{M}$ new cancer diagnoses, almost half are screen detectable [28]. Throughout the pandemic, among the many stages of cancer care that were delayed, screening evaluations had significant impact [2]. Though several of the larger cancer organizations, such as ASCO, SSO, and ASBrS, 
Fig. 2 a Risk of bias summary.

b Risk of bias graph $\mathbf{a}$

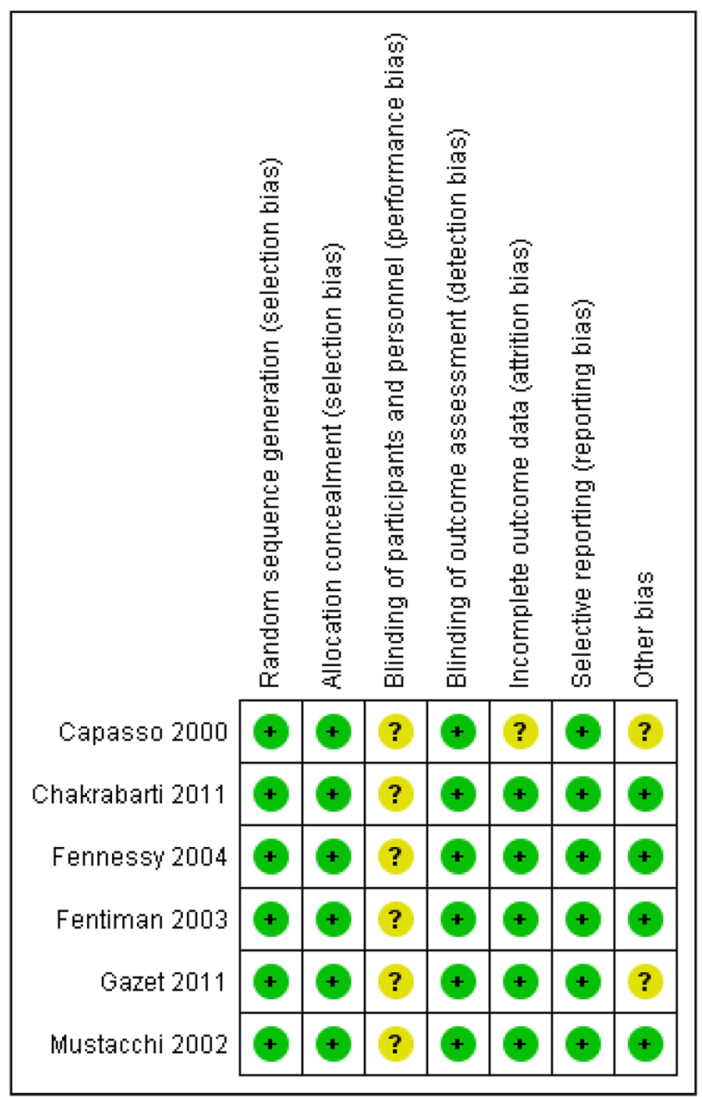

b

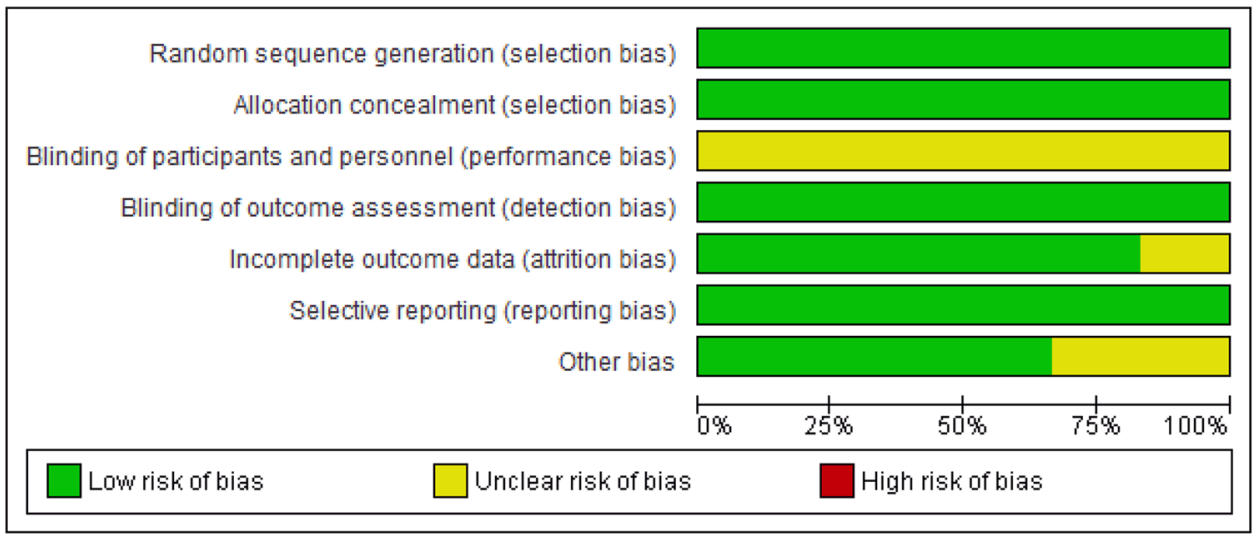

developed guidelines to try to preserve critical screening and surveillance, screening began to decline very early on in the pandemic, several months prior to the surge. According to IQVIA utilization data, there was a severe reduction in mammograms performed well before cessation at the height of the pandemic [29]. Surveillance and office visits were also decreased, as screening was low.

Overall, the diagnosis of new breast cancer cases during the peak of COVID-19 was impacted not only by low screening rates, but also by prior cases that were delayed in treatment. The potential impact due to the buildup of overdue screening is enormous and more than initially anticipated.
As we emerge from COVID-19, the recovery phase may not be just that. We are tasked with conducting care while the pandemic threats are still present. As we go forward to protect surgical patients from exposure and possible infection while elective surgeries have restarted, we look to prior efforts to prioritize care.

The main results of this meta-analysis show that PET alone was inferior to surgery combined with or without PET. Patients treated with surgery are at decreased risk for local recurrence with higher rates of both overall and breast-cancer-specific survival, and lower rates of both cancer-specific mortality and all-cause mortality. Though these outcomes 


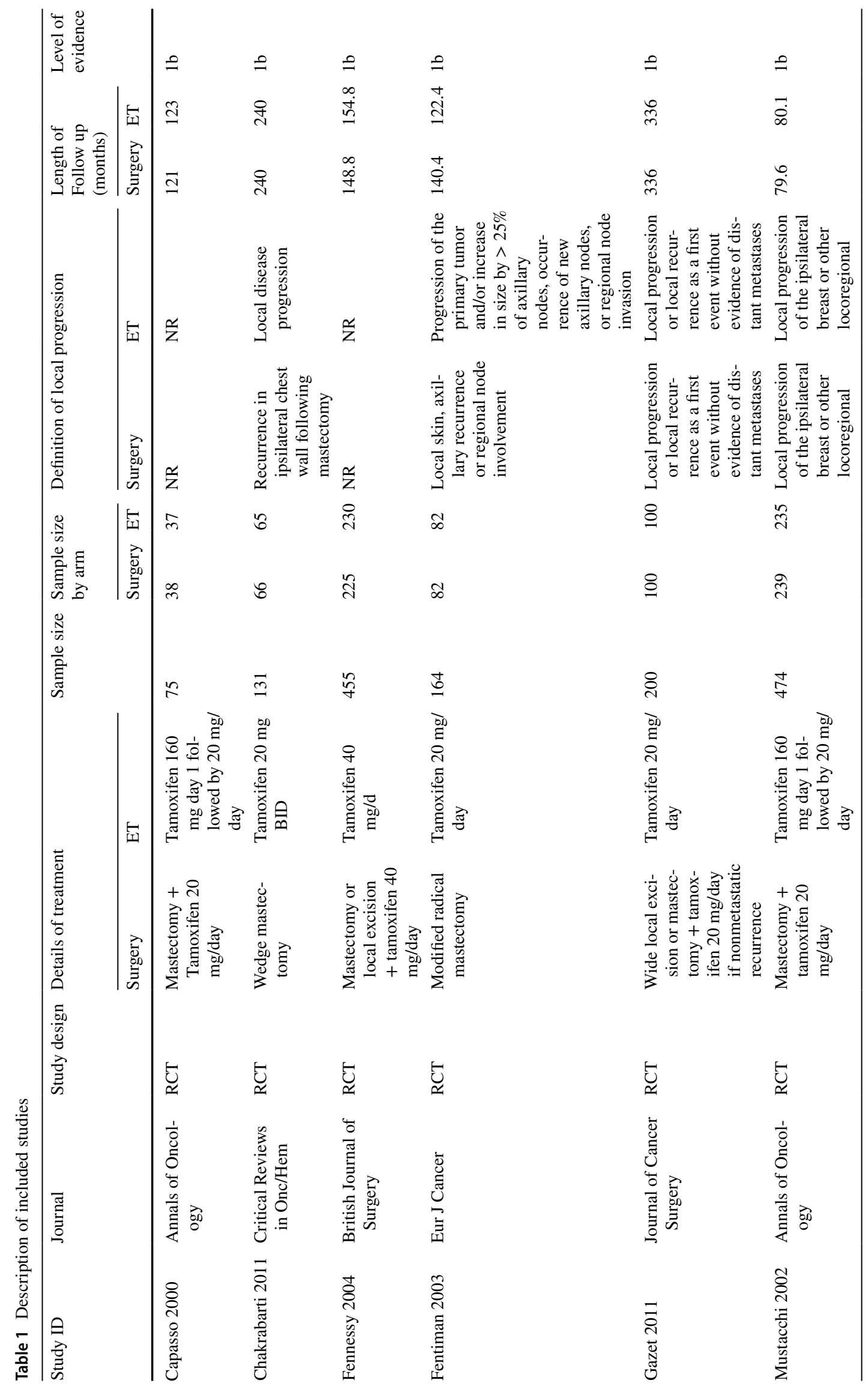


Table 2 Demographics and cancer-specific variables of the included studies

\begin{tabular}{|c|c|c|c|c|c|c|}
\hline \multirow[t]{2}{*}{ Study ID } & \multicolumn{2}{|l|}{ Age } & \multicolumn{2}{|l|}{ Lymph nodes } & \multicolumn{2}{|l|}{ Cancer stage } \\
\hline & Surgery & ET & Surgery & ET & Surgery & ET \\
\hline Capasso 2000 & NR & NR & NR & NR & NR & NR \\
\hline Chakrabarti 2011 & $>70$ & $>70$ & NR & NR & $\begin{array}{l}<4 \mathrm{~cm}^{2}: 18 \\
2-9 \mathrm{~cm}^{2}: 24 \\
-16 \mathrm{~cm}^{2}: 21 \\
-25 \mathrm{~cm}^{2}: 2\end{array}$ & $\begin{array}{l}<4 \mathrm{~cm}^{2}: 13 \\
2-9 \mathrm{~cm}^{2}: 35 \\
-16 \mathrm{~cm}^{2}: 16 \\
-25 \mathrm{~cm}^{2}: 2\end{array}$ \\
\hline Fennessy 2004 & 76 & 76 & $\begin{array}{l}\text { No palpable: } \\
179 \\
\text { Palpable: } 40 \\
\text { Not known: } 6\end{array}$ & $\begin{array}{l}\text { No palpable: } \\
191 \\
\text { Palpable: } 33 \text { Not } \\
\text { known: } 6\end{array}$ & $\begin{array}{l}\text { T1: } 48 \\
\text { T2: } 114 \\
\text { T3a: } 9 \\
\text { T4b: } 54\end{array}$ & $\begin{array}{l}\text { T1: } 38 \\
\text { T2: } 130 \\
\text { T3a: } 16 \\
\text { T4b: } 46\end{array}$ \\
\hline Fentiman 2003 & $>70$ & $>70$ & $\begin{array}{l}\text { N0: } 59 \\
\text { N1A: } 8 \\
\text { N1B:14 } \\
\text { Unknown:1 }\end{array}$ & $\begin{array}{l}\text { N0: } 57 \\
\text { N1A: } 11 \text { N1B: } \\
\text { 14 Unknown: } 0\end{array}$ & $\begin{array}{l}\text { T1: } 14 \\
\text { T2: } 57 \\
\text { T3: } 9 \\
\text { T4: } 1 \\
\text { Unknown: } 1\end{array}$ & $\begin{array}{l}\text { T1: } 12 \\
\text { T2: } 56 \\
\text { T3: } 12 \\
\text { T4: } 1 \text { Unknown: } \\
1\end{array}$ \\
\hline Gazet 2011 & 76.9 & 75.4 & NR & NR & $\begin{array}{l}\text { T1: } 22 \\
\text { T2: } 48 \\
\text { T3: } 23 \\
\text { T4: } 7\end{array}$ & $\begin{array}{l}\text { T1: } 17 \\
\text { T2: } 52 \\
\text { T3: } 17 \\
\text { T4: } 14\end{array}$ \\
\hline Mustacchi 2002 & 76 & 77 & $\begin{array}{l}\text { N0: } 136 \\
\text { N1a: } 69 \\
\text { N1b: } 27 \\
\text { N3: } 1 \\
\text { Unknown: } 6\end{array}$ & $\begin{array}{l}\text { N0: } 150 \\
\text { N1a: } 66 \text { N1b: } \\
\text { 15 } \\
\text { N3: 0; } \\
\text { Unknown: } 4\end{array}$ & $\begin{array}{l}<2 \mathrm{~cm}: 135 \\
2-5 \mathrm{~cm}: 96 \\
>5 \mathrm{~cm}: 2\end{array}$ & $\begin{array}{l}<2 \mathrm{~cm}: 127 \\
2-5 \mathrm{~cm}: 101 \\
>5 \mathrm{~cm}: 3\end{array}$ \\
\hline
\end{tabular}

a

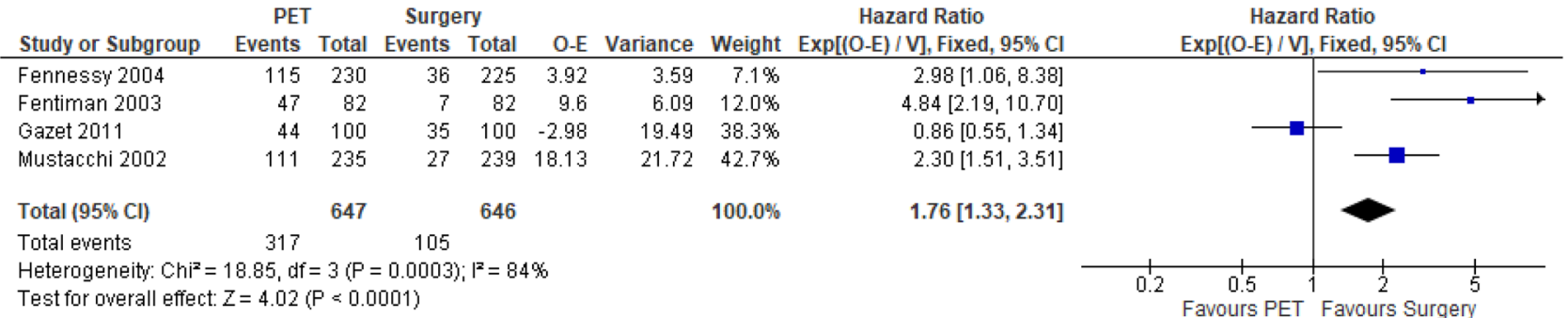

b

\begin{tabular}{|c|c|c|c|c|c|c|c|c|c|c|c|}
\hline Study or Subgroup & \multicolumn{2}{|c|}{ PET } & \multicolumn{2}{|c|}{ Surgery } & O-E & Variance & Weight & $\begin{array}{l}\text { Hazard Ratio } \\
(\mathrm{O}-\mathrm{E}) / \mathrm{V}] \text {, Fixed, } 95 \% \mathrm{Cl}\end{array}$ & \multicolumn{3}{|c|}{$\begin{array}{c}\text { Hazard Ratio } \\
\text { Exp[(O-E) / V], Fixed, } 95 \% \mathrm{Cl}\end{array}$} \\
\hline Capasso 2000 & 13 & 37 & 9 & 35 & 1.71 & 5.32 & $9.0 \%$ & $1.38[0.59,3.23]$ & & & \\
\hline Chakrabarti 2011 & 23 & 65 & 27 & 66 & -3.41 & 12.42 & $21.0 \%$ & $0.76[0.44,1.33]$ & & & \\
\hline Fentiman 2003 & 3 & 82 & 13 & 82 & -0.7 & 2.44 & $4.1 \%$ & $0.75[0.21,2.63]$ & & & \\
\hline Gazet 2011 & 22 & 100 & 25 & 100 & -2.88 & 11.7 & $19.8 \%$ & $0.78[0.44,1.39]$ & & & \\
\hline Mustacchi 2002 & 51 & 235 & 59 & 239 & -10.74 & 27.35 & $46.2 \%$ & $0.68[0.46,0.98]$ & & & \\
\hline Total $(95 \% \mathrm{Cl})$ & & 519 & & 522 & & & $100.0 \%$ & $0.76[0.59,0.98]$ & & & \\
\hline $\begin{array}{l}\text { Heterogeneity: } \mathrm{Chi}^{2}= \\
\text { Test for owerall effect }\end{array}$ & $\begin{array}{l}2.28, \mathrm{df}= \\
Z=2.08\end{array}$ & $\begin{array}{l}4(P= \\
P=0.0\end{array}$ & $0.68) ; i^{2}=$ & $=0 \%$ & & & & & 0.2 & $\begin{array}{c}0.5 \\
\text { Favours PET }\end{array}$ & 1 Favours Sur \\
\hline
\end{tabular}

Fig. 3 Forest plots comparing PET and surgery: a local recurrence (progression) rates. b Distant recurrence (progression) rates

support upfront surgery in treating patients diagnosed with early breast cancer, these studies also shed light onto a potential window of time that may be acceptable to treat patients with PET in an effort to postpone surgery.

How long is too long? Of the six studies that reported on time to local recurrence, the mean time to local progression was 2.8 years from the initiation of endocrine therapy (range: 1.1-5.8 years). Therefore, it may be acceptable to treat patients with PET alone for this time period of 2.8 years before undergoing surgery without local recurrence. However, a conservative approach for 


\begin{tabular}{|c|c|c|c|c|c|c|c|c|c|}
\hline Study or Subgroup & \multicolumn{2}{|c|}{ PET } & \multicolumn{2}{|c|}{ Surgery } & O-E & Variance & Weight & $\begin{array}{c}\text { Hazard Ratio } \\
\text { Exp[(O-E) / V], Fixed, } 95 \% \mathrm{Cl}\end{array}$ & $\begin{array}{c}\text { Hazard Ratio } \\
\text { Exp }[(\mathrm{O}-\mathrm{E}) / \mathrm{V}] \text {, Fixed, } 95 \% \mathrm{Cl}\end{array}$ \\
\hline Chakrabarti 2011 & 0 & 65 & 2 & 66 & -0.54 & 0.5 & $0.3 \%$ & $0.34[0.02,5.43]$ & 4 \\
\hline Fennessy 2004 & 66 & 235 & 43 & 230 & 21.71 & 85.27 & $57.5 \%$ & $1.29[1.04,1.59]$ & \\
\hline Fentiman 2003 & 22 & 82 & 32 & 82 & 11.88 & 13.04 & $8.8 \%$ & $2.49[1.45,4.28]$ & \\
\hline Gazet 2011 & 0 & 100 & 0 & 100 & 0 & 0 & & Not estimable & \\
\hline Mustacchi 2002 & 109 & 235 & 91 & 239 & -0.97 & 49.6 & $33.4 \%$ & $0.98[0.74,1.30]$ & 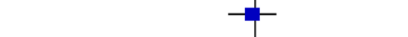 \\
\hline Total (95\% Cl) & & 717 & & 717 & & & $100.0 \%$ & $1.24[1.06,1.46]$ & \\
\hline Total events & 197 & & 168 & & & & & & \\
\hline $\begin{array}{l}\text { Heterogeneity: } \mathrm{Chi}^{2} \\
\text { Test for overall effec }\end{array}$ & $\begin{array}{l}10.02, \mathrm{df} \\
z=2.63\end{array}$ & $\begin{array}{l}=3(P= \\
P=0.0\end{array}$ & $\begin{array}{l}=0.02) ; 1^{2} \\
08)\end{array}$ & $70 \%$ & & & & & $\begin{array}{lclr}0.05 & 0.2 & 1 & 5 \\
& \text { Favours Surgery } & \text { Favours PET }\end{array}$ \\
\hline
\end{tabular}

b

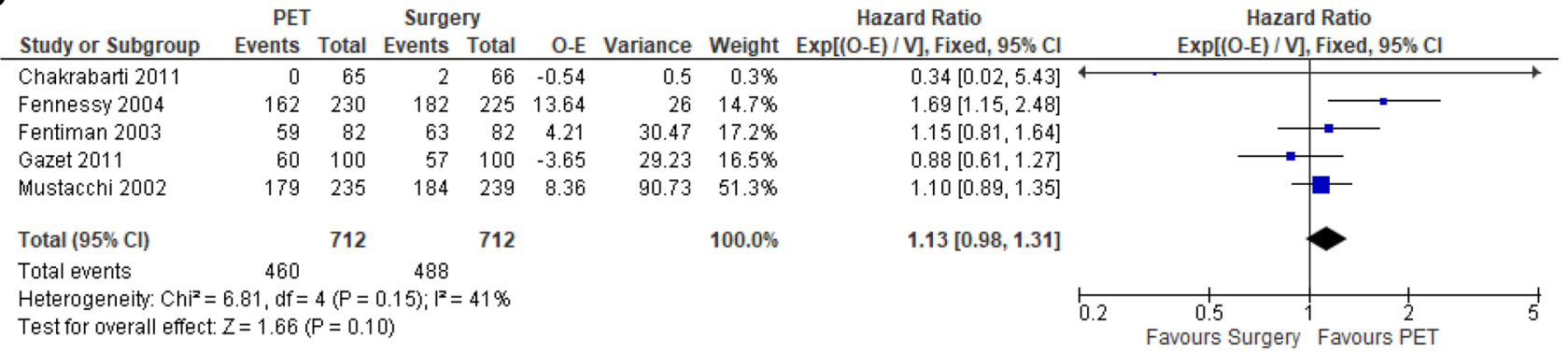

Fig. 4 Forest plots comparing PET and surgery: a overall survival rates. b Breast cancer-specific survival rates

\begin{tabular}{|c|c|c|c|c|c|c|c|c|c|c|c|c|}
\hline \multirow{2}{*}{ Study or Subgroup } & \multicolumn{2}{|c|}{ PET } & \multicolumn{2}{|c|}{ Surgery } & \multirow[b]{2}{*}{ O-E } & \multirow[b]{2}{*}{ Variance } & \multirow[b]{2}{*}{ Weight } & \multirow[t]{2}{*}{$\begin{array}{c}\text { Hazard Ratio } \\
\text { Exp[(O-E) } / \mathrm{V}] \text {. Fixed, } 95 \% \mathrm{Cl}\end{array}$} & \multirow{2}{*}{\multicolumn{3}{|c|}{$\begin{array}{c}\text { Hazard Ratio } \\
\text { Exp[(O-E) / V }] \text {, Fixed, } 95 \% \mathrm{Cl}\end{array}$}} & \\
\hline & Events & Total & Events & Total & & & & & & & & \\
\hline Chakrabarti 2011 & 63 & 65 & 66 & 66 & 4.33 & 32.23 & $13.3 \%$ & $1.14[0.81,1.62]$ & & & & \\
\hline Fennessy 2004 & 187 & 230 & 159 & 225 & 21.71 & 85.27 & $35.2 \%$ & $1.29[1.04,1.59]$ & & & & \\
\hline Fentiman 2003 & 50 & 82 & 60 & 82 & -17.18 & 27.27 & $11.3 \%$ & $0.53[0.37,0.78]$ & & & & \\
\hline Gazet 2011 & 60 & 100 & 57 & 100 & 4.55 & 29.23 & $12.1 \%$ & $1.17[0.81,1.68]$ & & & & \\
\hline Mustacchi 2002 & 144 & 235 & 130 & 239 & 8.57 & 68.32 & $28.2 \%$ & $1.13[0.89,1.44]$ & & & & \\
\hline Total $(95 \% \mathrm{Cl})$ & & 712 & & 712 & & & $100.0 \%$ & $1.09[0.97,1.24]$ & & & & \\
\hline Total events & 504 & & 472 & & & & & & & & & \\
\hline \multicolumn{8}{|c|}{$\begin{array}{l}\text { Heterogeneity: Chi }=16.72, \mathrm{df}=4(\mathrm{P}=0.002) ;\left.\right|^{2}=76 \% \\
\text { Test for overall effect: } Z=1.41(\mathrm{P}=0.16)\end{array}$} & & 0.2 & $\begin{array}{l}0.5 \\
\text { Favours PET }\end{array}$ & $1 \quad 2$ & 5 \\
\hline \multicolumn{3}{|c|}{ PET } & \multicolumn{2}{|c|}{ Surgery } & \multirow[b]{2}{*}{ O-E } & \multirow[b]{2}{*}{ Variance } & \multirow[b]{2}{*}{ Weight } & \multirow{2}{*}{$\begin{array}{l}\text { Hazard Ratio } \\
(\mathrm{O}-\mathrm{E}) / \mathrm{V}] \text {, Fixed, } 95 \% \mathrm{Cl}\end{array}$} & \multirow{2}{*}{\multicolumn{3}{|c|}{$\begin{array}{c}\text { Hazard Ratio } \\
\text { Exp[(O-E) / V }] \text {, Fixed, } 95 \% \mathrm{Cl}\end{array}$}} & \\
\hline Study or Subgroup & Events & Total & Events & Total & & & & & & & & \\
\hline Chakrabarti 2011 & 40 & 65 & 42 & 66 & -4.38 & 20.49 & $21.5 \%$ & $0.81[0.52,1.25]$ & & $=$ & 7 & \\
\hline Fennessy 2004 & 68 & 230 & 43 & 225 & 13.64 & 26.29 & $27.6 \%$ & $1.68[1.15,2.46]$ & & & & \\
\hline Gazet 2011 & 40 & 100 & 43 & 100 & -3.83 & 20.72 & $21.8 \%$ & $0.83[0.54,1.28]$ & & & & \\
\hline Mustacchi 2002 & 56 & 235 & 55 & 239 & 4.43 & 27.75 & $29.1 \%$ & $1.17[0.81,1.70]$ & & & & \\
\hline Total $(95 \% \mathrm{Cl})$ & & 630 & & 630 & & & $100.0 \%$ & $1.11[0.91,1.36]$ & & & & \\
\hline Total events & 204 & & 183 & & & & & & & & & \\
\hline $\begin{array}{l}\text { Heterogeneity: } \mathrm{Chi}^{2}= \\
\text { Test for overall effect }\end{array}$ & $\begin{array}{l}8.41, \mathrm{df}= \\
Z=1.01\end{array}$ & $\begin{array}{l}3(P= \\
P=0.3\end{array}$ & $0.04) ; 1^{2}=$ & $=64 \%$ & & & & & 0.2 & $\begin{array}{l}0.5 \\
\text { Favours PET }\end{array}$ & 1 Favours Sur & 5 \\
\hline
\end{tabular}

Fig. 5 Forest plots comparing PET and surgery: a all-cause mortality rates. b Cancer-specific mortality rates

treatment with PET alone, avoiding surgery, in terms of time to development of local recurrence is 1.1 years.

Has the SARS-CoV-2 pandemic lead the way to what may become the standard of care for early and noninvasive breast cancer? Possibly not, as our meta-analysis demonstrates. While the surgical profession is not known for its agility historically, this unprecedented pandemic brought leaders together on both local and national levels. Breast cancer care was quickly modified without knowledge of impact on oncologic outcomes. New ways to care for patients included telehealth, and technology was offered by surgeons [1,4]. Surgeons were pushed to make treatment decisions based on public health concerns rather than solely on the patient's diagnosis. Virtual tumor boards were formed and there were increased numbers of regional webinars to discuss patient management in a broader sense. Though many clinical trials 

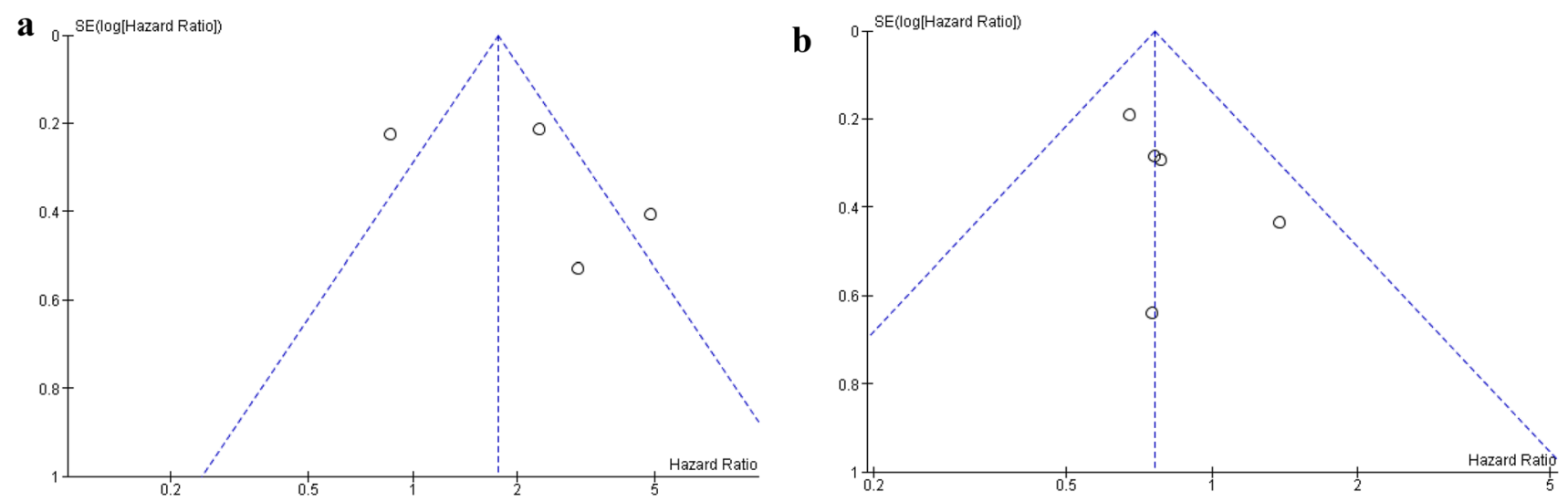

Fig. 6 Funnel plots of hazard ratio and standard error of log hazard ratio: a local recurrence (progression) rates. b Distant recurrence (progression) rates

were suspended, patients who already started investigational drugs were monitored remotely. Although, we cannot conclude omission of surgery altogether for otherwise operable breast cancer, there is a window of time that may be allotted to safely allow emergence from pandemic.

\section{Limitations}

This meta-analysis has several limitations. First, all studies only included women aged $\geq 70$ years, making it difficult to extrapolate how younger patients may fare on solely PET. Additionally, the included studies did not stratify outcomes by tumor stage nor nodal status. Therefore, while we hypothesize that patients with less aggressive tumors may have more favorable outcomes on PET, this was not possible to prove. Similarly, the studies did not provide detailed information on treatment regimen in the PET arms of each trial when recurrence was identified. Further, how recurrence was defined was not known. This made it difficult to sum and compare outcomes of the PET arms of each study.

\section{Conclusion}

PET alone is inferior to surgery in the treatment of operable, early-stage invasive breast cancer. However, it may be acceptable to delay curative breast cancer surgery without risk of progression for 1.1 years or longer. Going forward, the National Cancer Database (NCDB) will further elucidate the long-term oncologic impact of the disruption of cancer care during the pandemic. Additional research is needed to assess the effectiveness and safety of the alteration of care. If nothing else, the pandemic demonstrated that it is possible for providers, payers, and patients to come together to facilitate change safely, and without progression of disease for at least a short time interval.
Supplementary Information The online version contains supplementary material available at https://doi.org/10.1007/s12282-021-01302-4.

Author contributions All authors have contributed to the following: Substantial contributions to the conception or design of the work; or the acquisition, analysis, or interpretation of data for the work; AND Drafting the work or revising it critically for important intellectual content; AND Final approval of the version to be published; AND Agreement to be accountable for all aspects of the work in ensuring that questions related to the accuracy or integrity of any part of the work are appropriately investigated and resolved.

Funding This study has not received any funding.

\section{Declarations}

Conflict of interest All authors declare they have no conflicts of interest.

Ethical approval This article does not contain any studies with human participants performed by any of the authors.

Informed consent Not applicable as this is a summary design study.

\section{References}

1. Hollander JE, Carr BG. Virtually perfect? Telemedicine for covid19. N Engl J Med. 2020;382(18):1679-81. https://doi.org/10. 1056/NEJMp2003539.

2. ASBrS, Acr. ASBrS and ACR joint statement on breast screening exams during the COVID-19 Pandemic. 2020.

3. Curigliano G, Joao M, Poortmans P, Gentilini O. Recommendations for triage, prioritization and treatment of breast cancer patients during the COVID-19 pandemic. 2020.

4. Gasparri ML, Gentilini OD, Lueftner D, Kuehn T, Kaidar-Person O, Poortmans P. Changes in breast cancer management during the Corona Virus Disease 19 pandemic: an international survey of the European Breast Cancer Research Association of Surgical Trialists (EUBREAST). Breast. 2020;52:110-5. https://doi.org/ 10.1016/j.breast.2020.05.006. 
5. Hilton J, Arnaout A, Clemons M. Primary endocrine therapy as an approach for patients with localized breast cancer deemed not to be surgical candidates. Curr Opin Support Palliat Care. 2014;8(1):53-8. https://doi.org/10.1097/SPC.0000000000000026.

6. Dietz J, Katharine Yao Uh, Kurtzman S, et al. Recommendations for Prioritization, Treatment and Triage of Breast Cancer Patients During the COVID-19 Pandemic: Executive Summary Version 1.0 Surgical Oncology: Medical Oncology: Radiation Oncology: Corresponding Author. 2020. https://www.accc-cancer.org/docs/ document/cancer-program-fundamentals/oh-cco. Accessed $14 \mathrm{Jul}$ 2020.

7. Martí C, Sánchez-Méndez JI. Neoadjuvant endocrine therapy for luminal breast cancer treatment: a first-choice alternative in times of crisis such as the COVID-19 pandemic. Ecancermedicalscience. 2020;14:1027. https://doi.org/10.3332/ecancer.2020.1027.

8. Li J-J, Shao Z-M. Endocrine therapy as adjuvant or neoadjuvant therapy for breast cancer: selecting the best agents, the timing and duration of treatment. Chinese Clin Oncol. 2016;5(3):40. https:// doi.org/10.21037/cco.2016.03.24.

9. Pritchard KI. Endocrine therapy for breast cancer. Oncol (Williston Park). 2000;14(4):483-92. https://doi.org/10.1002/central/ CN-01738137/full.

10. Wylie S, Ravichandran D. A UK national survey of breast surgeons on primary endocrine therapy of early operable breast cancer. Ann R Coll Surg Engl. 2013;95(5):353-6. https://doi.org/10. 1308/003588413X13629960045832.

11. Punglia RS, Hughes KS, Muss HB. Management of older women with early-stage breast cancer. Am Soc Clin Oncol Educ B. 2015;35:48-55. https://doi.org/10.14694/edbook_am.2015.35.48.

12. Hind D, Wyld L, Reed MW. Surgery, with or without tamoxifen, vs tamoxifen alone for older women with operable breast cancer: cochrane review. Br J Cancer. 2007;96(7):1025-1029. http://search.ebscohost.com/login.aspx?direct=true\&AuthType $=$ ip, $\mathrm{sso} \& \mathrm{db}=\mathrm{mdc} \& \mathrm{AN}=17285133 \&$ site $=$ ehost-live $\&$ custid $=\mathrm{s} 9001$ 925.

13. Johnston SJ, Cheung K-L. The role of primary endocrine therapy in older women with operable breast cancer. Futur Oncol. 2015;11(10):1555-65. https://doi.org/10.2217/fon.15.13.

14. Book Series C, Higgins JP, Green S. Cochrane handbook for systematic reviews of interventions the cochrane collaboration ${ }^{\circledR}$. 2021.

15. Moher D, Liberati A, Tetzlaff J, Altman DG. Preferred reporting items for systematic reviews and meta-analyses: the PRISMA statement. Int J Surg. 2010;8(5):336-41. https://doi.org/10.1016/j. ijsu.2010.02.007.

16. Stroup DF, Berlin JA, Morton SC, et al. Meta-analysis of observational studies in epidemiology: a proposal for reporting. J Am Med Assoc. 2000;283(15):2008-12. https://doi.org/10.1001/jama. 283.15.2008

17. Roberts S, Rojas A, Gachabayov MCM. Protocol for a systematic review assessing surgery versus primary endocrine therapy in operable breast cancer. Prep for Pandemic. Int J Surg Protoc. 2020.

18. Higgins JPT, Thompson SG, Deeks JJ, Altman DG. Measuring inconsistency in meta-analyses. Br Med J. 2003;327(7414):55760. https://doi.org/10.1136/bmj.327.7414.557.
19. Capasso I, Nuuzzo F, Labonia V, Landi G, Rossi E, de Matteis A. Surgery + tamoxifen versus tamoxifen as treatment of stage I and II breast cancer in over to 70 years old women: ten years followup. Ann Oncol. 2000;11(4):20.

20. Chakrabarti J, Kenny FS, Syed BM, Robertson JFR, Blamey $\mathrm{RW}$, Cheung KL. A randomised trial of mastectomy only versus tamoxifen for treating elderly patients with operable primary breast cancer-final results at 20-year follow-up. Crit Rev Oncol Hematol. 2011;78(3):260-4. https://doi.org/10.1016/j.critrevonc. 2010.04.006.

21. Fennessy M, Bates T, MacRae K, Riley D, Houghton J, Baum M. Late follow-up of a randomized trial of surgery plus tamoxifen versus tamoxifen alone in women aged over 70 years with operable breast cancer. Br J Surg. 2004;91(6):699-704. https://doi.org/ 10.1002/bjs.4603.

22. Gazet JC, Sutcliffe R. A randomised trial comparing tamoxifen vs surgery in patients over the age of 70 with operable breast cancer-final results after 28 years of follow-up. Eur J Surg Oncol. 2011;37(9):754-7. https://doi.org/10.1016/j.ejso.2011.06.011.

23. Mustacchi G, Milani S, Pluchinotta A, De Matteis A, Rubagotti A, Perrota A. Tamoxifen or surgery plus tamoxifen as primary treatment for elderly patients with operable breast cancer: the G.R.E.T.A. Trial. Group for research on endocrine therapy in the elderly. Anticancer Res. 1994;14(5):2197-2200. https://doi.org/ 10.1002/central/CN-00109861/full.

24. Fentiman IS, Van Zijl J, Karydas I, et al. Treatment of operable breast cancer in the elderly: a randomised clinical trial EORTC 10850 comparing modified radical mastectomy with tumorectomy plus tamoxifen. Eur J Cancer. 2003;39(3):300-8. https://doi.org/ 10.1016/S0959-8049(02)00672-X.

25. Quiroga-García V, Cirauqui-Cirauqui B, Bugés-Sánchez C, et al. Primary hormone therapy in elderly women with hormonesensitive locoregional breast cancer: endocrine therapy alone is a reasonable alternative in selected patients. Breast Care. 2015;10(3):179-83. https://doi.org/10.1159/000382112.

26. Diaz A, Sarac BA, Schoenbrunner AR, Janis JE, Pawlik TM. Elective surgery in the time of COVID-19. Am J Surg. 2020;219(6):900-2. https://doi.org/10.1016/j.amjsurg.2020.04. 014.

27. Common Cancer Sites-Cancer Stat Facts. 2020. https://seer. cancer.gov/statfacts/html/common.html. Accessed 11 Aug 2020.

28. A new way to screen for cancer-Harvard Health. 2021. https:// www.health.harvard.edu/cancer/a-new-way-to-screen-for-cancer. Accessed 29 Jan 2021.

29. IQVIA. Shifts in healthcare demand, delivery and care during the COVID-19 era. 2020. www.iqvia.com/insights/the-iqvia-institute/ covid-19/shifts-in-healthcare-demand-delivery-and-care-duringthe-covid-19-era. 2020.

Publisher's Note Springer Nature remains neutral with regard to jurisdictional claims in published maps and institutional affiliations. 